\title{
Evidence that the M1 Muscarinic Receptor Subtype Mediates the Effects of Oxotremorine on Masculine Sexual Behavior
}

\author{
Socorro Retana-Marquez, M.S. and Javier Velazquez-Moctezuma M.D.
}

The cholinergic system participates in the regulation of masculine sexual behavior, mainly through the muscarinic system. Recently, muscarinic receptors have been subdivided into at least two subtypes, M1 and M2, according to their differential affinity for pirenzepine. In this study, we analyzed the possible participation of the M1 muscarinic receptor subtype on masculine sexual behavior regulation. In the first experiment, trihexyphenidyl, a specific M1 antagonist, was administered to experienced adult male rats in a wide range of doses (from 0.1 to $6.4 \mathrm{mg} / \mathrm{kg}$ ). No modification was observed in any of the male sexual behavior parameters recorded, with the exception of the highest dose at which an increase of the intromission frequency and a decrease of the ejaculation frequency were observed. In the second experiment, trihexyphenidyl was administered in several doses (from 0.2 to $1.6 \mathrm{mg} / \mathrm{kg}$ ), before the administration of oxotremorine, a muscarinic agonist, at a dose that readily facilitates masculine sexual behavior. Trihexyphenidyl completely prevented the facilitatory effects of oxotremorine even at the smallest dose used. These results strongly suggest that the M1 muscarinic receptor subtype participates in the cholinergic facilitation of masculine sexual behavior.

[Neuropsychopharmacology 9:267-270, 1993]
KEY WORDS: Cholinergic regulation; Muscarinic receptors; Oxotremorine; Trihexyphenidyl; Masculine sexual behavior

It has been shown that the cholinergic system has a role in the regulation of sexual behavior (Bitran and Hull 1987; Hull et al. 1988a; 1988b; Dohanich et al. 1991). Oxotremorine (OXO), a muscarinic receptor agonist, reduces the ejaculation threshold by decreasing intromission frequency (IF) and ejaculation latency (EL) (Ahlenius and Larsson 1985; Bitran and Hull 1987; Hull et al. 1988a, 1988b) and increasing the ejaculation frequency (EF) in intact male rats (Retana et al. 1993). As

From the Departamento de Biología de la Reproducción, Universidad Autónoma Metropolitana-Iztapalapa, Mexico City, Mexico.

Address correspondence to: Dr. Javier Velazquez-Moctezuma, Depto. Biol. Reprod., Universidad Autonoma Metropolitana-Iztapalapa, Purisima y Michoacan, Col. Vicentina, C.P. 09340, Del. Iztapalapa, Mexico City. D.F. Mexico.

Received January 25, 1993; revised June 25, 1993; accepted July 19 , 1993. could be expected, these facilitatory effects of $\mathrm{OXO}$ are completely blocked by pretreatment with the muscarinic receptor antagonist scopolamine (SCO- $\mathrm{HCl}$ ) (Ahlenius and Larsson 1985; Hull et al. 1988b). In addition, $\mathrm{SCO}-\mathrm{HCl}$ by itself induces an increase in mount and intromission latency and a decrease in the percentage of sexually active males in a dose-related manner, as well as a decrease in EF (Hull et al. 1988b; Retana et al. 1993). These data support the notion that the cholinergic system participates in the regulation of masculine sexual behavior mainly through the muscarinic system.

During the early 1980s, it was demonstrated that the muscarinic receptor population could be subdivided into at least two major subclasses according to its affinity for the antagonist pirenzepine (Hammer et al. 1980; Hammer and Giachetti 1982). Since then, drugs acting at cholinergic synapsis have been analyzed for their different affinity with a specific subpopulation of muscarinic receptors (for review, see Wolfe 1989). 
Trihexyphenidyl (TRI) is a muscarinic antagonist that has been used for years as coadjuvant in the treatment of movement disorders in humans (Burke et al. 1986; Doshay and Constable 1949; Rubinstein 1978). Trihexyphenidyl is a selective blocker of the M1 muscarinic receptor subtype (Avissar and Schreiber 1989; Dörje et al. 1991; Giachetti et al. 1986; Lambrecht et al. 1988; Tien and Wallace 1985) and some reports suggest that it readily crosses the blood-brain barrier (Goyal 1989; McInnis and Petursson 1984; Valevski et al. 1992).

In the present study, we analyze the possible participation of the M1 muscarinic receptor subtype both in the regulation of masculine sexual behavior and in the mediation of the facilitatory effects of OXO on masculine sexual behavior.

\section{METHODS}

Male Wistar adult rats weighing between 300 and $350 \mathrm{~g}$ were housed, five per cage $(50 \times 30 \times 20 \mathrm{~cm})$, under constant temperature and humidity conditions. The colony room was maintained on a 12-hour/12-hour reverse light-dark cycle (lights off: 9 AM). Food and water were available ad libitum.

To assess the effect of TRI by itself on masculine sexual behavior, the following groups were tested. Group A $(n=10)$ received three lower doses $(0.1,0.2$, and $0.4 \mathrm{mg} / \mathrm{kg}$ ) of TRI or a vehicle (distilled water) control injection. Group B $(n=10)$ received four higher doses $(0.8,1.6,3.2$, and $6.4 \mathrm{mg} / \mathrm{kg})$ or a vehicle control injection.

To assess the interaction between the muscarinic M1 blockade and the facilitatory effect of OXO, the following groups were tested. Group C $(n=10)$ animals were pretreated with the muscarinic peripheral blocker $\mathrm{SCO}-\mathrm{MBr}(3 \mathrm{mg} / \mathrm{kg}) 15$ minutes before the administration of OXO $(0.4 \mathrm{mg} / \mathrm{kg})$ or saline. This experiment was performed to corroborate the facilitatory effects of OXO (Ahlenius and Larsson 1985; Retana et al. 1993). Group $\mathrm{D}(n=10)$ animals received four different doses of TRI $(0.2,0.4,0.8$, and $1.6 \mathrm{mg} / \mathrm{kg}) 15$ minutes before the administration of OXO $(0.4 \mathrm{mg} / \mathrm{kg})$.

Antagonists injections were made 45 minutes before the behavioral tests. This time period was selected because of TRI pharmacokinetics (Burke and Fahn, 1985) and to compare its effects with those of the unspecific muscarinic blocker $\mathrm{SCO}-\mathrm{HCl}$. The sequence of injections was randomized and a 1-week period elapsed between observations.

Behavioral testing was performed under dim red light illumination and began 3 hours after the onset of the dark phase of the cycle. Masculine sexual behavior was assessed by placing the male in a plexiglass arena ( $45 \mathrm{~cm}$ in diameter) for 5 minutes before a stimulus receptive female was presented. Female rats were brought into sexual receptivity by sequential treatment with estradiol benzoate $(5 \mu \mathrm{g} / .1 \mathrm{ml}$ oil, subcutaneously, once daily). To avoid stimulus habitation, the female rat was changed every 5 minutes (Wilson et al. 1963). After presentation of the female, the tests lasted 30 minutes. All subjects were previously tested and only those that displayed at least one ejaculation were included in the study. The following parameters were recorded: mount (ML), intromission (IL) and ejaculation(EL) latencies, mount (MF), intromission(IF), and ejaculation (EF) frequencies; and postejaculatory interval (PEI). Also, the following indexes were obtained: hit rate (HR), which was equal to (number of intromissions/number of intromissions plus number of mounts); average interintromission interval (AIII) (ejaculation latency/number of intromissions); average intercopulatory interval (AICI) (ejaculation latency/number of intromissions plus number of mounts). A full description of masculine sexual behavior parameters has been detailed elsewhere (Sachs and Meisel 1988).

Estradiol benzoate was purchased from Aldrich Chemical Co. (Milwaukee, WI). Scopolamine methyl bromide (SCO-MBr), oxotremorine sesquifumarate (OXO) and trihexyphenidyl hydrochloride (TRI) were obtained from Sigma Chemical Co. (St. Louis, MO). Estradiol was dissolved in methanol and resuspended in oil. It was subcutaneously administered in a volume of $.05 \mathrm{ml}$. Trihexyphenidyl was dissolved in distilled water. Both $\mathrm{SCO}-\mathrm{MBr}$ and $\mathrm{OXO}$ were dissolved in a $0.9 \%$ saline solution. These drugs were intraperitoneally administered in a volume of $0.2 \mathrm{ml}$.

Statistical analysis was performed using the Krushal-Wallis one-way analysis of variance followed by the Mann-Whitney $U$-test for comparisons between treatments and control.

\section{RESULTS}

Trihexyphenidyl did not modify most of the recorded parameters of masculine sexual behavior when applied systemically in a wide range of doses. When compared to the results obtained with vehicle administration, only the highest dose used $(6.4 \mathrm{mg} / \mathrm{kg})$ elicited significant changes, and those were restricted to an increase of IF in the first ejaculatory series and a decrease of the EF.

As it has been previously reported (Ahlenius and Larsson 1985; Retana et al. 1993), OXO effects were not prevented by the previous administration of the peripheral muscarinic antagonist $\mathrm{SCO}-\mathrm{MBr}$. The administration of OXO induced a decrease of IF and in EL, as well as an increase in EF.

Concerning the antagonistic actions of the M1 blocker, as can be seen in Figure $1 \mathrm{~A}$, the facilitatory effects of OXO in IF were completely prevented by TRI pretreatment, even with the smallest dose $(0.2 \mathrm{mg} / \mathrm{kg})$ 

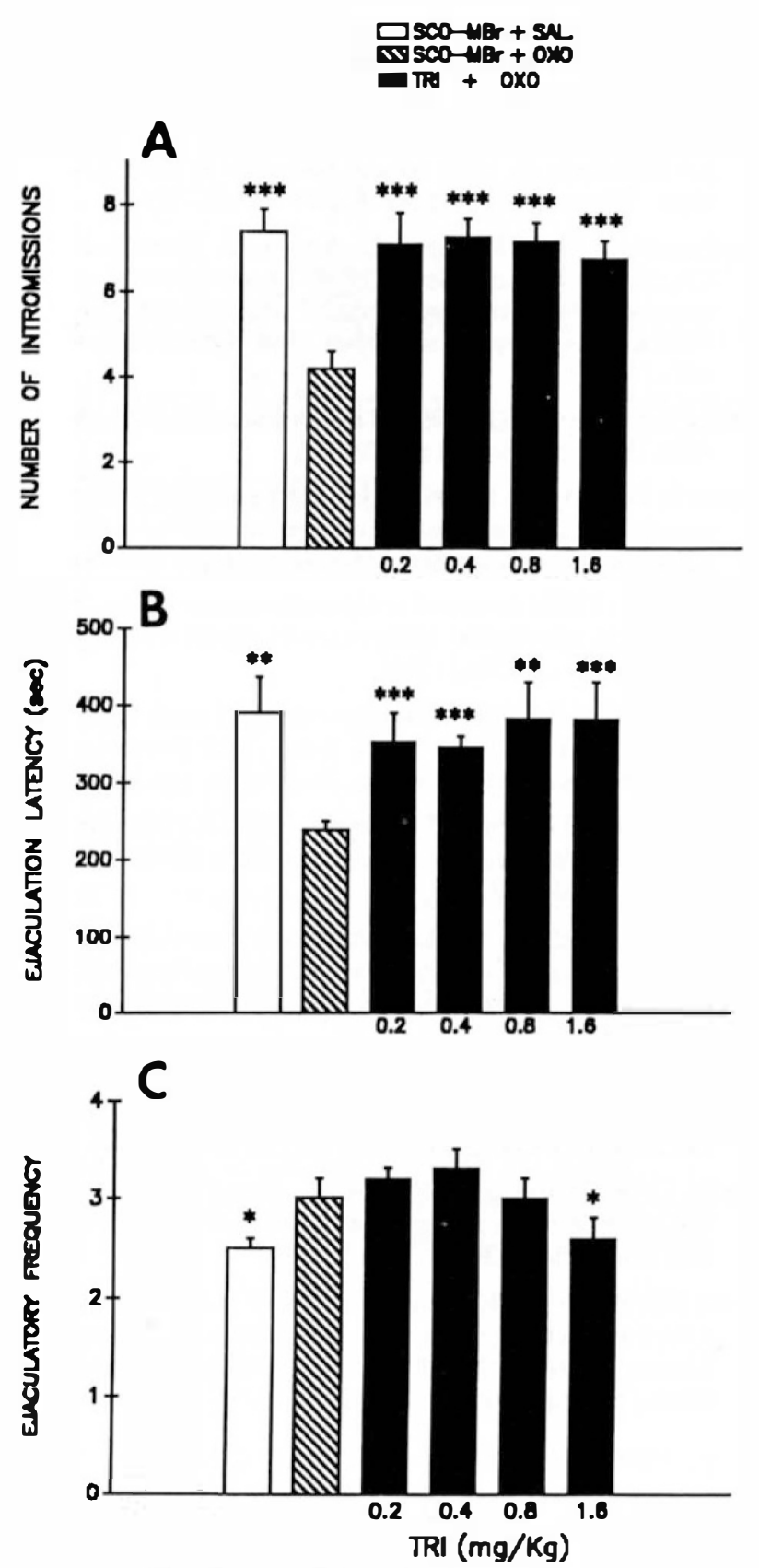

Mann Whitney U-teat compared to control. - $p$ < 0.05. $p$ ( 0.01 . p p $p$ ( 0.005 .

Figure 1. The significant decrease of intromission frequency (A) and ejaculation latency (B) induced by the administration of OXO $(0.4 \mathrm{mg} / \mathrm{kg})$ was prevented with all doses of TRI (from 0.2 to $1.6 \mathrm{mg} / \mathrm{kg}$ ) previously injected, but not by scopolamine methyl bromide $(3 \mathrm{mg} / \mathrm{kg})$. The significant increase of ejaculatory frequency induced by $\mathrm{OXO}(\mathrm{C})$ was inhibited by the previous administration of TRI only at the highest dose used $(1.6 \mathrm{mg} / \mathrm{kg})$, but not by SCO-MBr. Vehicle injection does not modify any of these parameters. Data are expressed as mean \pm SEM used. A similar inhibition of the facilitatory effects of OXO was also observed for the EL (Figure 1B).

On the other hand, low doses of TRI were not capable of suppressing the increase in EF elicited by OXO (Figure 1C). Blockade of this effect was obtained only with the highest dose of TRI $(1.6 \mathrm{mg} / \mathrm{kg})$ used.

\section{DISCUSSION}

The present results confirm previous evidence that the cholinergic system is implicated in the regulation of sexual behavior in male rats, mainly through muscarinic receptors as indicated by the facilitatory effects induced by OXO administration. Additionally, these data strongly suggest the notion that this cholinergic facilitation of masculine sexual behavior is mediated through the M1 muscarinic receptor subtype. When the M1 selective antagonist TRI was administered before the muscarinic agonist OXO, the facilitatory effects of this agonist on masculine sexual behavior were almost completely prevented, even with the smallest dose of TRI used.

On the other hand, it seems that selective blockade of the central and peripheral muscarinic M1 receptor subtype by itself is incapable of inducing any noticeable modifications in the masculine sexual behavior parameters recorded. At a very high dose, however, a significant increase of IF was observed as well as a decrease in $\mathrm{EF}$, which correlates exactly with the decrease of IF and the increase of EF observed with OXO, supporting the notion that intromission regulation and ejaculatory potential is linked to the M1 subtype.

There is evidence that pirenzepine, the prototype M1 muscarinic receptor antagonist, can reverse central OXO-induced effects on learning (Witkin et al. 1988). These data also support the M1 mediation of OXO effects.

The unspecific muscarinic antagonist $\mathrm{SCO}-\mathrm{HCl}$ causes a decrease in the percentage of sexually active males and a marked increase in mount or intromission latencies (Ahlenius and Larsson 1985; Retana et al. 1993). By itself, TRI did not induce those effects. These data open the possibility that the effects of SCO-HCl on male sexual behavior could be mediated by a different muscarinic receptor subtype. Thus, the effects that $\mathrm{M} 1$ and $\mathrm{M} 2$ agonists and $\mathrm{M} 2$ antagonists could produce on male sexual behavior remain to be studied to further understand the muscarinic mechanisms that regulate masculine sexual behavior.

\section{ACKNOWLEDGMENT}

The authors want to express their gratitude to Edith Monroy, MSc., for skillful advice in the preparation of the manuscript. 


\section{REFERENCES}

Ahlenius S, Larsson K (1985): Central muscarinic receptors and male rat sexual behavior: Facilitation by oxotremorine but not arecoline or pilocarpine in methscopolamine pretreated animals. Psychopharmacology 87:127-129

Avissar S, Schreiber G (1989): Muscarinic receptor subclassification and G-proteins: Significance for lithium action on affective disorders and for the treatment of the extrapyramidal side effects of neuroleptics. Biol. Psychiatry $26: 113-130$

Bitran D, Hull E (1987): Pharmacological analysis of male rat sexual behavior. Neurosci Biobehav Rev 11:365-389

Burke E, Fahn S (1985): Pharmacokinetics of trihexyphenidyl after short-term and long-term administration to dystonic patients. Ann. Neurol. 18:35-40

Burke R, Fahn S, Marsden D (1986): Torsion dystonia: A double blind, prospective trial of high-dosage trihexyphenidyl. Neurology 36:160-164

Dörje F, Wess J, Lambrecht G, Tacke R, Mustchler E, Brann M (1991): Antagonist binding profiles of five cloned human muscarinic receptor subtypes. J Pharmacol Exp Ther 256:727-733

Doshay L, Constable K (1949): Artane therapy for parkinsonism. JAMA 154:1317-1322

Giachetti A, Giraldo E, Ladinsky H, Montagna E (1986): Binding and functional profiles of the selective M1 muscarinic receptor antagonists trihexyphenidyl and dicyclomine. Br J Pharmacol 89:83-90

Goyal R (1989): Muscarinic receptor subtypes. Physiology and clinical implications. New Engl J Med 321:1022-1028

Hammer R, Berrie C, Birdsall N, Burgen A, Hulme E (1980): Pirenzepine distinguishes between different subclasses of muscarinic receptors. Nature 283:90-92

Hammer R, Giachetti A (1982): Muscarinic receptor subtypes: $\mathrm{M} 1$ and M2 biochemical and functional characterization. Life Sci 31:2991-2998

Hull E, Bitran D, Pehek E, Holmes G, Warner R, Band L, Clemens L (1988a): Brain localization of cholinergic influence on male sexual behavior in rats: Agonists. Pharmacol Biochem Behav 31:169-174

Hull E, Pehek E, Bitran D, Holmes G, Warner R, Band L, Bazzet T, Clemens L (1988b): Brain localization of cholinergic influence on male sexual behavior in rats: Antagonists. Pharmacol Biochem Behav 31:175-178

Lambrecht G, Feifel R, Moser U, Aasen AJ, Waelbroeck M, Christophe J, Mutschler E (1988): Stereoselectivity of the enantiomers of trihexyphenidyl and its methiodide at muscarinic receptor subtypes. Eur J Pharmacol 155: 167-170

McInnis M, Petursson H(1984): Trihexyphenidyl dependence. Acta Psychiatr Scand 69:538-542

Retana S, Domínguez E, Velazquez-Moctezuma J (1993): Muscarinic and nicotinic influences on masculine sexual behavior in rats. Pharmacol Biochem Behav 44:913-917

Rubinstein J (1978): Abuse of antiparkinsonism drugs. Feigning of extrapiramidal symptoms to obtain trihexyphenidyl. JAMA 239:2365-2366

Sachs B, Meisel R (1988): The physiology of male sexual behavior. In Knobil E, Neil J (eds), The physiology of Reproduction. Raven Press, New York, pp 1393-1482

Tien XY, Wallace LJ (1985): Trihexyphenidyl. Further evidence for muscarinic receptor subclassification. Biochem. Pharmacol 34:588-590

Valevski A, Gil-Ad I, Modai I, Apter A, Tyano S, Laron Z, Weizman A (1992): Neuroendocrine response to trihexyphenidyl in depressed patients. Clin Neuropharmacol 15:27-33

Wilson J, Kuehn R, Beach F (1963): Modification in the sexual behavior of male rats produced by changing the stimulus female. J Comp Physiol Psychol 56:636-644

Witkin J, Alvarado-Garcia R, Perez L, Witkin K (1988): Central oxotremorine antagonist properties of pirenzepine. Life Sci 42:2467-2473

Wolfe BB (1989): Subtypes of muscarinic cholinergic receptors: Ligand binding, functional studies, and cloning. In Brown JH (ed), The Muscarinic Receptors. Humana Press, New Jersey, pp 125-150 